\title{
Hernia In South Southern Nigeria: Five Year Retrospective Study.
}

\author{
Po Igwe,A Dodiyi-Manuel, Nu Nwankwo. \\ Department Of Surgery, University Of Port Harcourt Teaching Hospital(UPTH), Alakahia, Port Harcourt, \\ Rivers State, Nigeria.
}

\begin{abstract}
Background: Hernia occurs commonly in surgical practice. Common hernia cases include
Aims and Objectives: The purpose of this study is to determine the pattern of hernia diseases which were surgically treated in University of Port Harcourt Teaching Hospital.

Patients And Methods: This is a 4 year retrospective study of all adult patients with hernia diseases who were admitted into the surgical wards of University of Port Harcourt Teaching Hospital. Relevant data were retrieved and analyzed.

Results: A total of 386 patients had hernia between January 2009 to December 2012. In 2009 the highest number of patients were recorded 118 (30.6\%). This was followed by 2011 with 106 (27.5\%) of patients and subsequently, 2010 and 2012 with $89(21.8 \%)$ and 78 (20.2\%) respectively. There was male preponderance, males were $253(65.5 \%)$ and female were $133(34.5 \%)$ with a male to female ratio of 1.9:1. Most of these patients were aged 30-39 years 93 (24.1\%) followed by 20-29 years 91 (23.6\%), 40-49 years 73 (18.9\%), 50-59 years 49 (12.7\%), 60-69 years 36 (9.3\%), 70-79 years $20(5.2 \%)$, 10-19 years $16(4.1 \%), 80-89$ years and less than 10 years with 4 (1.0\%) each respectively. Most of the cases were done by Senior Registrars 221 (57.3\%) then Consultants 105 (27.2\%), while Registrars did 60 (15.5\%). The hernias were mostly inguinal with reducible right inguinal hernia constituting the highest 121(31.1\%), Reducible left inguinal hernias 81 (21.0\%), Obstructed right inguinal hernias were 44 (11.4\%), incisional hernia were 38 (9.8\%), umbilical hernia 27 (7.0\%), Bilateral inguinal hernias were $26(6.7 \%)$, epigastric hernias were $25(6.5 \%)$, obstructed supraumbilical hernias were 9 (2.3\%), left femoral hernias were 5 (1.3\%), obstructed left femoral and obstructed epigastric were both $4(1.0 \%)$ each and right femoral and bilateral femoral hernias were $1(0.3 \%)$ each respectively. The type of hernia repair done was nylon darn in $313(81.1 \%)$, those requiring both exploratory laparotomy and herniorrhaphy were 36 (9.3\%), bilateral herniorrhaphy was done in 15 (3.9\%). Mayo's type of repair was done in $9(2.3 \%)$ and repair with mesh was done in $4(1.0 \%)$ as well as in herniotomy. Primary repair in layers was in $3(0.8 \%)$. Herniorrhaphy with orchidectomy was $2(0.5 \%)$. The anaestheia done was mostly sub arachnoid block 297 (76.9\%), general anaesthesia was done in 69 (17.9\%), local infilteration was $18(4.7 \%)$, total intravenous anaesthesia (TIVA) and field block $1(0.3 \%)$ each. Most of the surgery lasted between 50-99 minutes 214 (55.4\%), then followed by less than 50 minutes 78 (20.2\%), 100-149 minutes 66 (17.1\%), 150-199 minutes 19 (4.9\%), 200-249 minutes 4 (1.0\%), 250-299 minutes 2 (0.5\%), 300-349, 350-399 and greater than 400 minutes with $1(0.3 \%)$ respectively.
\end{abstract}

Conclusion: Hernia in South Southern Nigeria has quite a large magnitude of clinical impact in our environment. The indirect inguinal hernia being the most common with male sex preponderace. Sub-aracnoid block is the most common form of anaesthesia utilized with most herniorrhaphies done by the senior registrars.

Keywords: Pattern; Adult Hernia diseases; University of Port Harcourt Teaching Hospital, South-Southern Nigeria.

\section{Introduction}

Hernia is an abnormal protrusion of a viscus through a potentially weak point or opening Hernia is derived from the Latin word for rupture. A hernia is defined as an abnormal protrusion of an organ or tissue through a defect in its surrounding walls. Although a hernia can occur at various sites of the body, these defects most commonly involve the abdominal wall, particularly the inguinal region. It has remained a common, important and major problem, imposing a heavy patient case-load on surgical services, particularly in Africa. A hernia can be internal or external. Diaphragmatic hernias, hernia through the mesentery, hiatus hernia and that through the "lateral space" following the fashioning of a colostomy are internal. The vast majority of hernias are external, appearing as obvious swellings to the exterior. The common ones are inguinal, umbilical, paraumbilical, epigastric, femoral and incisional. Rarer ones are lumbar, obturator, Spigelian and sciatic hernias.

There are two types of inguinal hernia, direct and indirect, which are defined by their relationship to the inferior epigastric vessels. Direct inguinal herniaoccur medial to the inferior epigastric vessels when abdominal contents herniate through a weak spot in the fascia of the posterior wall of the inguinal canal. The posterior wall of the inguinal canal is formed by the transversalis fascia. Indirect inguinal hernias occur when abdominal contents protrude through the deep inguinal ring, lateral to the inferior epigastric vessels; this may be caused by 
failure of embryonic closure of the processus vaginalis. A pantaloon hernia is said to occur when the abdominal contents protrude through the weak area in the posterior wall both medialand lateral to the inferior epigastric vessels on same side of the groin (that is when both direct and indirect hernia occur on same side).

In the case of the female, the opening of the superficial inguinal ring is smaller than that of the male. As a result, the possibility for hernias through the inguinal canal in males is much greater because they have a larger opening and therefore a much weaker wall through which the intestines may protrude.

Inguinal hernias belong to groin hernias, which also includefemoral hernias. A femoral hernia is not via the inguinal canal, but via the femoral canal, which normally allows passage of the common femoral artery and vein from the pelvis to the leg.

\section{Clinically a hernia may be classifiedthus:}

\section{Classification}

Reducible hernia: is one which can be pushed back into the abdomen by spontaneous or putting manual pressure to it.Irreducible hernia: is one which cannot be pushed back into the abdomen by applying manual pressure. Irreducible hernias are further classified into Obstructed hernia: this is one in which the lumen of the herniated part of intestine is obstructed but the blood supply to the herniating vicus is intact.

Incarcerated hernia: this is one in which adhesions develop between the wall of hernia sac and the wall of intestine. Strangulated hernia: this is one in which the blood supply of the herniating viscus is cut off, thus, leading to ischaemia. The lumen of the intestine may be patent or not. Nyhus has also classified hernia based on the defect in internal ring and posterior wall into the following Type I: Indirect inguinal hernia. In this type, the internal inguinal ring is normal (example is seen in paediatric hernia).

Type II: Indirect inguinal hernia.In this type, the internal inguinal ring is dilated but the posterior inguinal wall is intact. The inferior deep epigastric vessels not displaced

Type III: In this type there is a posterior wall is defect.

A. Direct inguinal hernia

B. Indirect inguinal hernia. The internal inguinal ring is dilated, medially encroaching on or destroying the transversalis fascia of Hesselbach's triangle (example is massive scrotal, sliding or pantaloon hernia)

C. Femoral hernia.

Type IV: In this type there is recurrent hernia.

A. Direct.

B. Indirect.

C. Femoral.

D. Combined.

\section{Aetiology of external hernias.}

Most of the time, hernias develop when pressure in the compartment of the residing organ is increased, and the boundary is weak or weakened.

- Weakening of containing membranes or muscles is usually congenital (which explains part of the tendency of hernias to run in families), and increases with age (for example, degeneration of the annulus fibrosus of the intervertebral disc), but it may be on the basis of other illnesses, such as Ehlers-Danlos syndrome or Marfan syndrome, stretching of muscles during pregnancy, losing weight in obese people, etc., or because of scars from previous surgery.

- Many conditions chronically increase intra-abdominal pressure, (pregnancy, ascites, COPD, dyschezia, benign prostatic hypertrophy) and hence abdominal hernias are very frequent. Increased intracranial pressure can cause parts of the brain to herniate through narrowed portions of the cranial cavity or through the foramen magnum. Increased pressure on the intervertebral discs, as produced by heavy lifting or lifting with improper technique, increases the risk of herniation.

Causes of hiatal hernia vary depending on each individual. Among the multiple causes, however, are the mechanical causes which include: poison, improper heavy weight lifting, hard coughing bouts, sharp blows to the abdomen, tight clothing and incorrect posture. ${ }^{[5]}$

Furthermore, conditions that increase the pressure of the abdominal cavity may also cause hernias or worsen the existing ones. Some examples would be: obesity, straining during a bowel movement or urination, chronic lung disease, and also, fluid in the abdominal cavity. ${ }^{[6]}$

Also, if muscles are weakened due to poor nutrition, smoking, and overexertion, hernias are more likely to occur.

The physiological school of thought contends that in the case of inguinal hernia, the above mentioned are only an anatomical symptom of the underlying physiological cause. They contend that the risk of hernia is 
due to a physiological difference between patients who suffer hernia and those who do not, namely the presence of aponeurotic extensions from the transversus abdominis aponeurotic arch. ${ }^{[7]}$

Hernias may result from congenital anomalies or may be acquired later in life. There are predisposing as well as precipitating factors. Inguinal hernias in children, nearly always the indirect type, are a result of defective obliteration of the patent processus vaginalis. The preponderance of right-sided hernias in males has been attributed to the later descent of the right testis' . Nwako has noted that $7 \%$ of hernias in male children are accompanied by undescended testes and nearly all undescended testes have a hernia component ${ }^{11}$. During the embryonic period before the completion of intestinal rotation, there is a herniation of abdominal content through the umbilicus into the extra embryonic coelem. At about the $10^{\text {th }}$ week of foetal life, the viscera normally return to the abdominal cavity. Following ligation of the umbilical cord at birth, the stump heals by granulation and organization. At birth, many infants will show a small umbilical hernia because this process has not been carried through to completion. In most of these children, spontaneous closure of the fascial defect occurs within the first four years 4,11 .

The aetiology of acquired hernias and the reasons for the high prevalence of the disease in adult Africans is more controversial. Several theories - genetic, anatomical and neuromuscular - have been proposed.

\section{The Genetic Theory:}

A survey among school children in Japan suggested increased hernia rates among children of same family. This is consistent with polygenic predisposition. Hernias were twice as common among twins as in the rest of the population. Bakwin's work in Britain does not support this. Belcher working in Accra also noted that one in every 55 Ghananian live births is a twin. This is twice the rate seen in non-Africans. Similarly, high twinning rate has been found among the Yorubas of western Nigeria as reported by Nylander. Thus in Africa where twins are frequent, the hernia rate may be correspondingly high. This may be as a result of inheritance.

\section{Anatomical Theory:}

An anatomical susceptibility to hernia development has been suggested by Zivanovic in East Africa. The relatively low public arch found in the African weakens the posterior inguinal wall and predisposes to the development of groin hernia. It is however, the opinion of Gogler that this factor comes into prominence after the age of 45 years.

\section{The Neuromuscular Theory:}

Recently, many investigators have suggested that a connective tissue abnormality may be involved in adult onset hernias. Abnormalities in the ultrastructure and the physiochemical properties of the collagen in patients with direct hernias suggest that the hernia is the one manifestation of a generalized abnormality in collagen metabolism ${ }^{4}$. Many works point to a reduced collagen synthesis and increased elastolysis as part of the aetiologic process of herniation in adults. Peacock has made a strong plea for further studies into these important and refreshing approaches to the study of external hernias.

In considering the development of a hernia in adults, it is important to remember that increased intraabdominal pressure is at least as important as the predisposing factors discussed above. Chronic cough, symptoms of obstructive uropathy and constipation may precede herniation. In particular, benign prostate enlargement and urethral stricture are two important conditions that should be considered in an adult seeking medical attention because of hernia in Africa.

\subsection{Symptoms and Signs:}

Groin hernias present as bulges in the groin area that can become more prominent when coughing, straining, or standing up. They are rarely painful, and the bulge commonly disappears on lying down. The inability to "reduce", or place the bulge back into the abdomen usually means the hernia is 'incarcerated'.

Significant pain is suggestive of obstructed or strangulated bowel. When the bowel is strangulated, the pain is persistent even in between the crest and trough cycle of colicky pain. There may also be an associated fever, unlike in simple obstruction where pain is intermittent and with no fever.

As the hernia progresses, contents of the abdominal cavity, such as the intestines, can descend into the hernia and run the risk of being trapped within the hernia. This may cause an intestinal obstruction when the lumen of the intestine is occluded. If the blood supply of the portion of the intestine caught in the hernia is compromised, the hernia is deemed "strangulated" and gut ischemia and gangrene can result. This may lead to potentially fatal consequences. The timing of complications is not predictable. Emergency surgery for incarceration and strangulation carry much higher risk than planned, "elective" procedures. However, the risk of incarceration is low, evaluated at $0.2 \%$ per year. 


\section{Anesthesia for Groin Herniorrhaphy:}

The type of anesthesia used for inguinal herniorrhaphy is variable, depending primarily on the personal preference of the surgeon. Laparoscopic herniorrhaphy is the exception as general endotracheal anesthesia is primarily mandated by the pneumoperitoneum. Epidural anesthesia has been used, especially in high-risk patients, but is rare. Open inguinal herniorrhaphy through a groin incision can be performed under local or regional anesthesia, which is one of the strongest arguments for open herniorrhaphy when compared to laparoscopic herniorrhaphy.

In Port Harcourt, external hernia is the most common cause of intestinal obstruction. This was reported by Dodiyi-Manuel in Braithwaite Memorial Specialist Hospital and Etawo et al in University of Port Harcourt Teaching Hospital'.

\section{Aim And Objectives}

Aim:

The aim was to retrospectively determine the magnitude and pattern of adult inguinal hernia in University of Port Harcourt Teaching Hospital, Rivers State, and South Southern Nigeria. The types of repair offered to the patient and compare with other studies.

\subsection{Study Design.}

\section{Methodology}

The study was set up as a retrospective study to obtain demographic information and datain disease related variables.

1. Demographic data included: age, sex, marital status, educational level, main occupation, religion, ethnic nationalities.

2. Disease related variables included:

a) History of symptoms, duration and signs found. Other parameters are as stated in folder.

c) Follow -up after the procedure at 1 week and 2 weeks for early complications. Detecting long term or late complications such as recurrence was based on the period under study.

Ethical approval for the study was sought and obtained prior to commencement of the study.

\section{Study Site.}

The study patients folder were retrieved from the medical records of University of PortHarcourt Teaching Hospital (UPTH). Findings in theatre were noted including type of repair of posterior wall. UPTH serves as a referral centre for Rivers State and the neighbouring Bayelsa, Abia, Akwa Ibom, Delta and Imo States. These States have heterogeneous population consisting of several ethnic nationalities. Rivers State alone has a population of about 5.1 million people (2006 National population census).

\section{Study Population.}

The study Population consisted of both old and new cases seen within a specified year period of January 2009 t0 December 2012. These were estimated consecutive patients presenting with symptomatic hernia to the surgical and general outpatient clinics of the hospital.

Inclusion Criteria. All adult hernia, excluding paediatric surgical hernias. Patients who were included in the study were patients with hernia using the Nyhus classification. All patients admitted and treated for hernia in Upth. Some patients may have huge or giant hernias.

Kombo BB, Allison AB Giant inguino-scrotal hernias seen at the University of Port Harcourt Teaching Hospital. NJM 2013; 22:317-318

\section{Analysis Population.}

The analysis population consisted of all the subjects whose folders were retrieved and analyzed to have undergone herniorrhaphy.

Retrieval of folders was done.

\section{Statistical Analysis.}

Data was analyzed using SPSS (Statistical package for social sciences) version 16.0 Statistical package. Continuous variables were compared by student t-tests. The results were presented as Mean \pm Standard deviation, percentages and tables while proportions or categorical parameters was analyzed with the Chi-Square 
test or two tailed Fischer's exact test as appropriate. A P value of $\leq 0.05$ was considered statistically significant. Pearson's correlation was used to assess relationship between two variables

\section{Results}

A total of 386 patients had hernia between January 2009 to December 2012. In 2009 the highest number of patients were recorded 118 (30.6\%). This was followed by 2011 withj 106 (27.5\%) of patients and subsequently, 2010 and 2012 with $89(21.8 \%)$ and $78(20.2 \%)$ respectively. Table 1. There was male preponderance, males were $253(65.5 \%)$ and female were $133(34.5 \%)$ with a male to female ratio of 1.9:1. Table 2. Most of these patients were aged 30-39 years 93 (24.1\%) followed by 20-29 years $91(23.6 \%), 40-49$ years $73(18.9 \%), 50-59$ years $49(12.7 \%), 60-69$ years $36(9.3 \%), 70-79$ years $20(5.2 \%), 10-19$ years 16 (4.1\%), 80-89 years and less than 10 years with $4(1.0 \%)$ each respectively. Table 3 . Most of the cases were done by Senior Registrars 221 (57.3\%) then Consultants 105 (27.2\%), while Registrars did 60 (15.5\%) Fig 1.Table 4 . The hernias were mostly inguinal with reducible right inguinal hernia constituting the highest 121(31.1\%), Reducible left inguinal hernias 81 (21.0\%), Obstructed right inguinal hernias were $44(11.4 \%)$, incisional hernia were $38(9.8 \%)$, umbilical hernia 27 (7.0\%), Bilateral inguinal hernias were $26(6.7 \%)$, epigastric hernias were $25(6.5 \%)$, obstructed supra-umbilical hernias were $9(2.3 \%)$, left femoral hernias were 5 (1.3\%), obstructed left femoral and obstructed epigastric were both $4(1.0 \%)$ each and right femoral and bilateral femoral hernias were $1(0.3 \%)$ each respectively. Table 5 . The type of hernia repair done was nylon darn in 313 $(81.1 \%)$, those requiring both exploratory laparotomy and herniorrhaphy were $36(9.3 \%)$, bilateral herniorrhaphy was done in $15(3.9 \%)$. Mayo's type of repair was done in $9(2.3 \%)$ and repair with mesh was done in $4(1.0 \%)$ as well as in herniotomy. Primary repair in layers was in $3(0.8 \%)$. Herniorrhaphy with orchidectomy was $2(0.5 \%)$. Table 6 . The anaestheia done was mostly sub arachnoid block 297 (76.9\%), general anaesthesia was done in $69(17.9 \%)$, local infilteration was $18(4.7 \%)$, total intravenous anaesthesia (TIVA) and field block $1(0.3 \%)$ each. Table 7. Most of the surgery lasted between 50-99 minutes $214(55.4 \%)$, then followed by less than 50 minutes 78 (20.2\%), 100-149 minutes 66 (17.1\%), 150-199 minutes 19 (4.9\%), 200249 minutes $4(1.0 \%), 250-299$ minutes $2(0.5 \%), 300-349,350-399$ and greater than 400 minutes with 1 $(0.3 \%)$ respectively. Table 8 . Most complications noted were scrotal hematoma, followed by wound infection. Recurrence was not clearly stated or documented. Fig 2-9 showed charts of results above.

\begin{tabular}{|c|c|c|c|c|c|}
\hline \multicolumn{6}{|l|}{ Year } \\
\hline & & Frequency & Percent & Valid Percent & $\begin{array}{l}\text { Cumulative } \\
\text { Percent }\end{array}$ \\
\hline \multirow[t]{5}{*}{ Valid } & 2009 & 118 & 30.6 & 30.6 & 30.6 \\
\hline & 2010 & 84 & 21.8 & 21.8 & 52.3 \\
\hline & 2011 & 106 & 27.5 & 27.5 & 79.8 \\
\hline & 2012 & 78 & 20.2 & 20.2 & 100.0 \\
\hline & Total & 386 & 100.0 & 100.0 & \\
\hline
\end{tabular}

Table 1.

\begin{tabular}{|c|c|c|c|c|c|}
\hline \multicolumn{6}{|l|}{ Sex } \\
\hline & & Frequency & Percent & Valid Percent & $\begin{array}{l}\text { Cumulative } \\
\text { Percent }\end{array}$ \\
\hline \multirow{3}{*}{ Valid } & $\mathrm{M}$ & 253 & 65.5 & 65.5 & 65.5 \\
\hline & $\mathrm{F}$ & 133 & 34.5 & 34.5 & 100.0 \\
\hline & Total & 386 & 100.0 & 100.0 & \\
\hline
\end{tabular}

Table 2.

\begin{tabular}{|l|l|l|l|l|l|}
\hline \multicolumn{2}{|l|}{ Age } & Frequency & $\begin{array}{l}\text { Percen } \\
\text { t }\end{array}$ & Valid Percent & $\begin{array}{l}\text { Cumulativ } \\
\text { e Percent }\end{array}$ \\
\hline \multirow{3}{*}{ Valid } & Less than 10 years & 4 & 1.0 & 1.0 & 1.0 \\
\cline { 2 - 6 } & $10-19$ & 16 & 4.1 & 4.1 & 5.2 \\
\cline { 2 - 6 } & $20-29$ & 91 & 23.6 & 23.6 & 28.8 \\
\cline { 2 - 6 } & $30-39$ & 93 & 24.1 & 24.1 & 52.8 \\
\cline { 2 - 6 } & $40-49$ & 73 & 18.9 & 18.9 & 71.8 \\
\cline { 2 - 6 } & $50-59$ & 49 & 12.7 & 12.7 & 84.5 \\
\cline { 2 - 6 } & $60-69$ & 36 & 9.3 & 9.3 & 93.8 \\
\cline { 2 - 6 } & $70-79$ & 20 & 5.2 & 5.2 & 99.0 \\
\cline { 2 - 6 } & $80-89$ & 4 & 1.0 & 1.0 & 100.0 \\
\cline { 2 - 6 } & Total & 386 & 100.0 & 100.0 & \\
\hline
\end{tabular}


Table 3.

\begin{tabular}{|l|l|l|l|l|l|}
\hline Cadre & & Frequency & Percent & Valid Percent & $\begin{array}{l}\text { Cumulative } \\
\text { Percent }\end{array}$ \\
\hline \multirow{3}{*}{ Valid } & Registrar & 60 & 15.5 & 15.5 & 15.5 \\
\cline { 2 - 6 } & Senior Registrar & 221 & 57.3 & 57.3 & 72.8 \\
\cline { 2 - 6 } & Consultant & 105 & 27.2 & 27.2 & 100.0 \\
\cline { 2 - 6 } & Total & 386 & 100.0 & 100.0 & \\
\hline
\end{tabular}

Table 4.

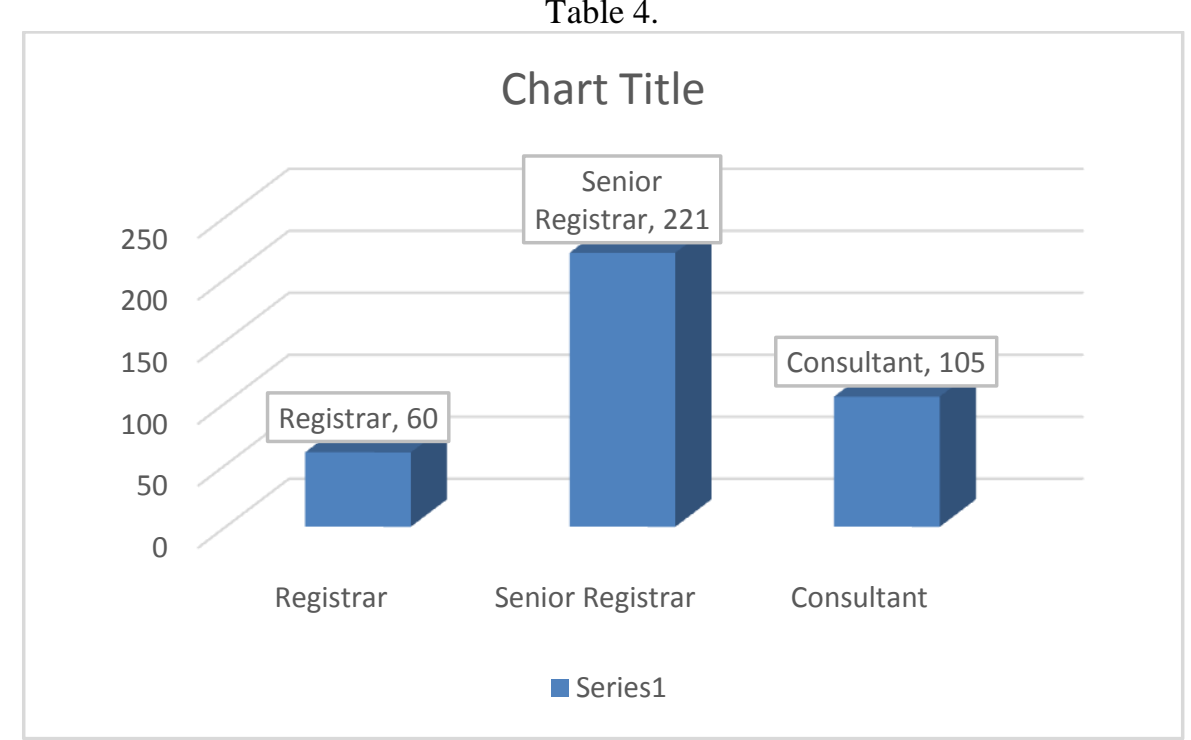

Fig 1. The Cadre

\begin{tabular}{|c|c|c|c|c|c|}
\hline \multicolumn{6}{|c|}{ Diagnosis } \\
\hline & & Frequency & Percent & Valid Percent & $\begin{array}{l}\text { Cumulative } \\
\text { Percent }\end{array}$ \\
\hline \multirow[t]{14}{*}{ Valid } & Left inguinal hernia & 81 & 21.0 & 21.0 & 21.0 \\
\hline & Right inguinal hernia & 121 & 31.3 & 31.3 & 52.3 \\
\hline & Bilateral inguinal hernia & 26 & 6.7 & 6.7 & 59.1 \\
\hline & Umbilical hernia & 27 & 7.0 & 7.0 & 66.1 \\
\hline & Left femoral hernia & 5 & 1.3 & 1.3 & 67.4 \\
\hline & Right femoral hernia & 1 & .3 & .3 & 67.6 \\
\hline & Bilateral femoral hernia & 1 & .3 & .3 & 67.9 \\
\hline & Epigastric hernia & 25 & 6.5 & 6.5 & 74.4 \\
\hline & Incisional hernia & 38 & 9.8 & 9.8 & 84.2 \\
\hline & $\begin{array}{l}\text { Obstructed right inguinal } \\
\text { hernia }\end{array}$ & 44 & 11.4 & 11.4 & 95.6 \\
\hline & $\begin{array}{l}\text { Obstructed left inguinal } \\
\text { hernia }\end{array}$ & 4 & 1.0 & 1.0 & 96.6 \\
\hline & $\begin{array}{ll}\text { Obstructed } & \text { supra- } \\
\text { umbilical hernia } & \\
\end{array}$ & 9 & 2.3 & 2.3 & 99.0 \\
\hline & $\begin{array}{l}\text { Obstructed epigastric } \\
\text { hernia }\end{array}$ & 4 & 1.0 & 1.0 & 100.0 \\
\hline & Total & 386 & 100.0 & 100.0 & \\
\hline
\end{tabular}

Table 5

\begin{tabular}{|l|l|l|l|l|l|}
\hline Operation & \multicolumn{5}{|c|}{} \\
\hline \multirow{3}{*}{ Valid } & Herniorrhaphy & Frequency & Percent & Valid Percent & Cumulative Percent \\
\cline { 2 - 6 } & Herniotomy & 313 & 81.1 & 81.1 & 81.1 \\
\cline { 2 - 6 } & Mayo's repair & 4 & 1.0 & 1.0 & 82.1 \\
\cline { 2 - 6 } & Primary repair in layers & 9 & 2.3 & 2.3 & 84.5 \\
\cline { 2 - 6 } & Mesh repair & 4 & .8 & .8 & 85.2 \\
\cline { 2 - 6 } & Bilateral herniorrhaphy & 15 & 1.0 & 1.0 & 86.3 \\
\cline { 2 - 6 } & $\begin{array}{l}\text { Herniorrhaphy and others } \\
\text { (orchidectomy) }\end{array}$ & 2 & .5 & .5 & 90.2 \\
\cline { 2 - 6 } & $\begin{array}{l}\text { Exploratory laparotomy and } \\
\text { hernoirrhaphy }\end{array}$ & 36 & 9.3 & 9.3 & 100.0 \\
\cline { 2 - 6 } & Total & 386 & 100.0 & 100.0 & \\
\hline
\end{tabular}


Hernia In South Southern Nigeria: Five Year Retrospective Study.

Table 6.

\begin{tabular}{|l|l|l|l|l|l|}
\hline \multicolumn{2}{|c|}{ Anaesthesia } & Frequency & Percent & Valid Percent & $\begin{array}{l}\text { Cumulative } \\
\text { Percent }\end{array}$ \\
\hline \multirow{4}{*}{ Valid } & General (subarachnoid & 297 & 17.9 & 17.9 & 17.9 \\
\cline { 2 - 6 } & $\begin{array}{l}\text { Spinal } \\
\text { block) }\end{array}$ & 69 & 76.9 & 76.9 & 94.8 \\
\cline { 2 - 6 } & Local infilteration & 18 & 4.7 & 4.7 & 99.5 \\
\cline { 2 - 6 } & $\begin{array}{l}\text { Total intravenous } \\
\text { anaesthesia (TIVA) }\end{array}$ & 1 & .3 & .3 & 99.7 \\
\cline { 2 - 6 } & Field block & 1 & .3 & .3 & 100.0 \\
\cline { 2 - 6 } & Total & 386 & 100.0 & 100.0 & \\
\hline
\end{tabular}

Table 7

\begin{tabular}{|l|l|l|l|l|l|}
\hline \multicolumn{2}{|c|}{} & Frequency & Percent & Valid Percent & $\begin{array}{l}\text { Cumulative } \\
\text { Percent }\end{array}$ \\
\hline \multirow{5}{*}{ Valid } & Less than 50 minutes & 78 & 20.2 & 20.2 & 20.2 \\
\cline { 2 - 6 } & $50-99$ & 214 & 55.4 & 55.4 & 75.6 \\
\cline { 2 - 6 } & $100-149$ & 66 & 17.1 & 17.1 & 92.7 \\
\cline { 2 - 6 } & $150-199$ & 19 & 4.9 & 4.9 & 97.7 \\
\cline { 2 - 6 } & $200-249$ & 4 & 1.0 & 1.0 & 98.7 \\
\cline { 2 - 6 } & $250-299$ & 2 & .5 & .5 & 99.2 \\
\cline { 2 - 6 } & $300-349$ & 1 & .3 & .3 & 99.5 \\
\cline { 2 - 6 } & $350-399$ & 1 & .3 & .3 & 99.7 \\
\cline { 2 - 6 } & 23 & 1 & .3 & .3 & 100.0 \\
\cline { 2 - 6 } & Total & 386 & 100.0 & 100.0 & \\
\hline
\end{tabular}

Table 8.

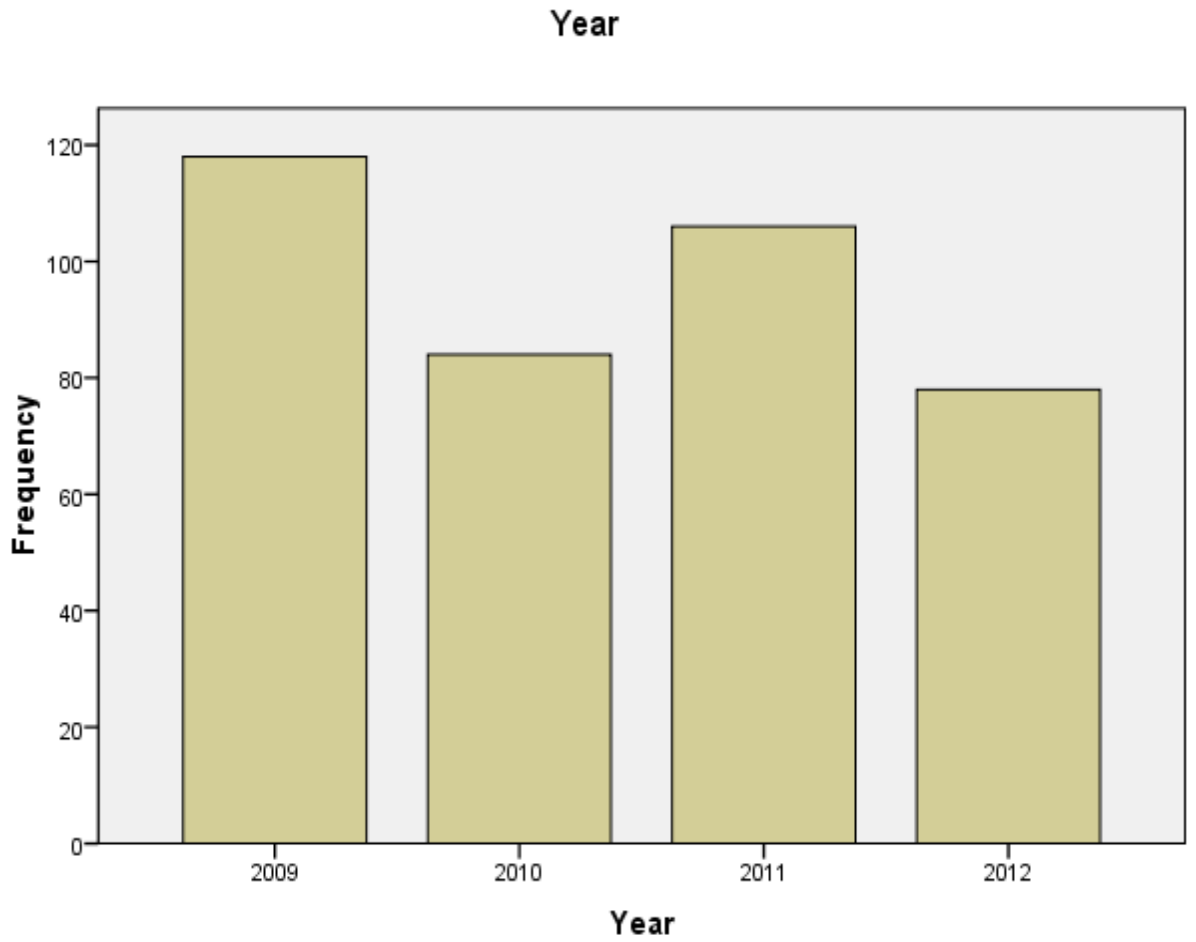

Fig 2 Year 


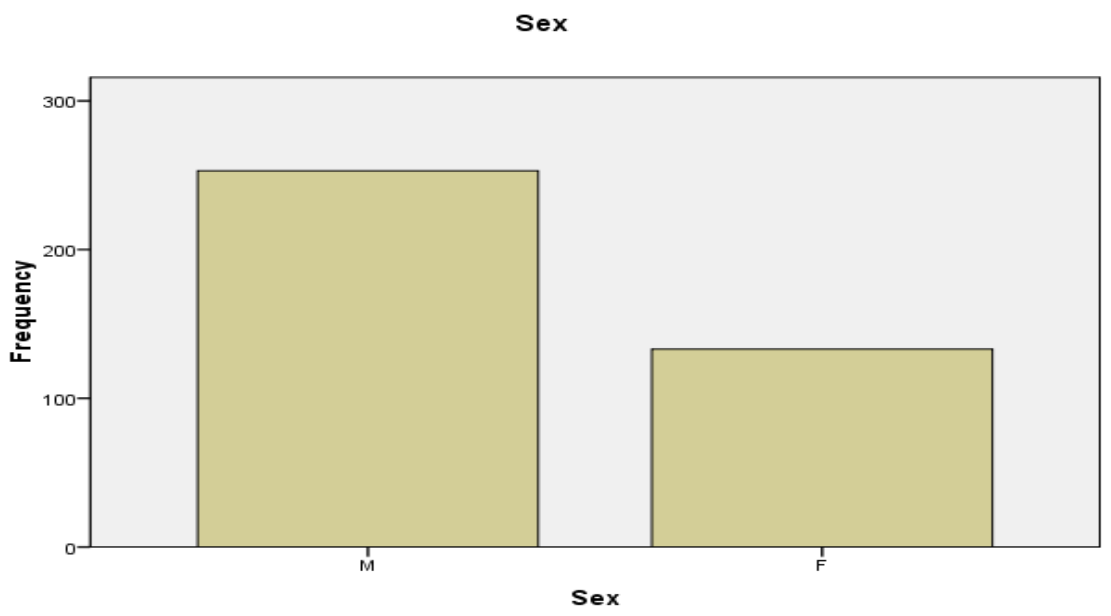

Fig 3 Sex

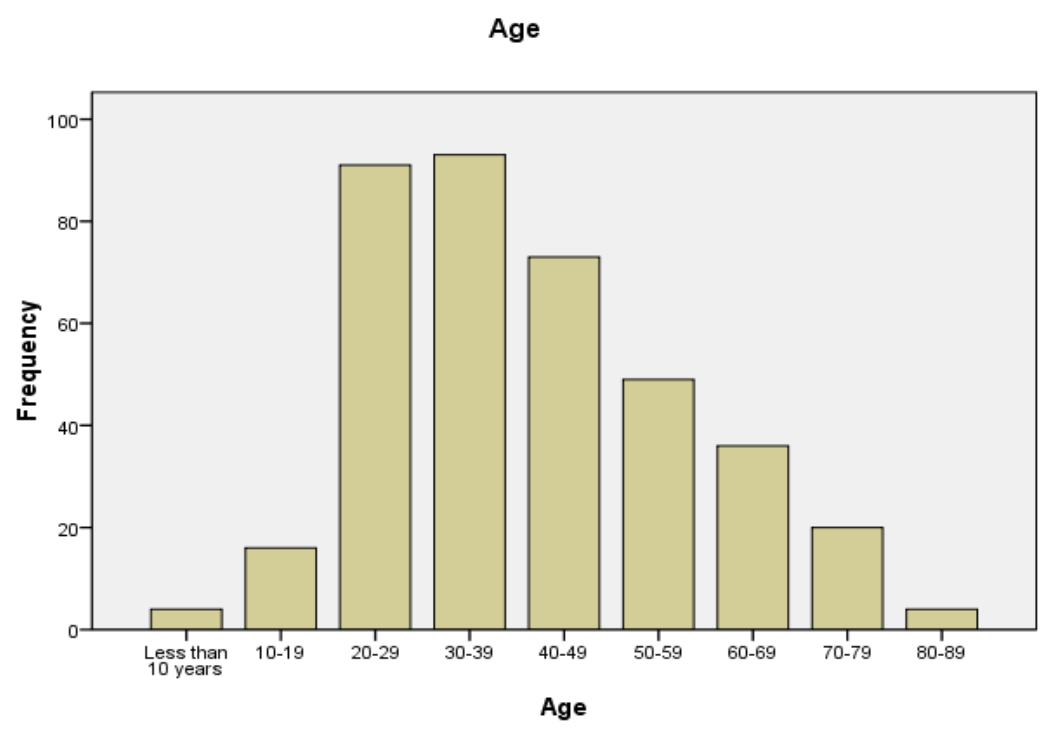

Fig 4. Age

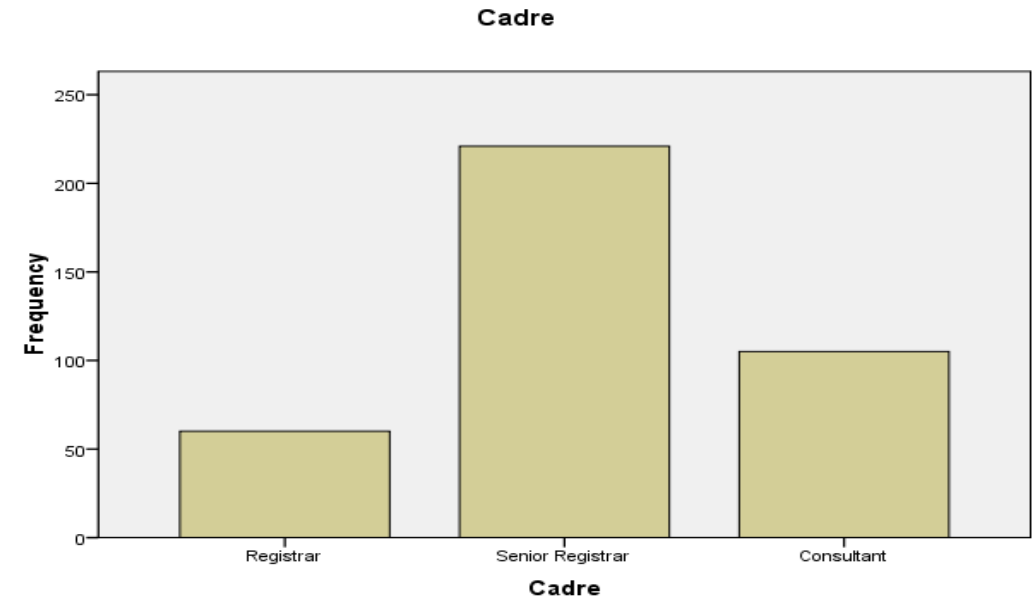

Fig 5 Cadre 


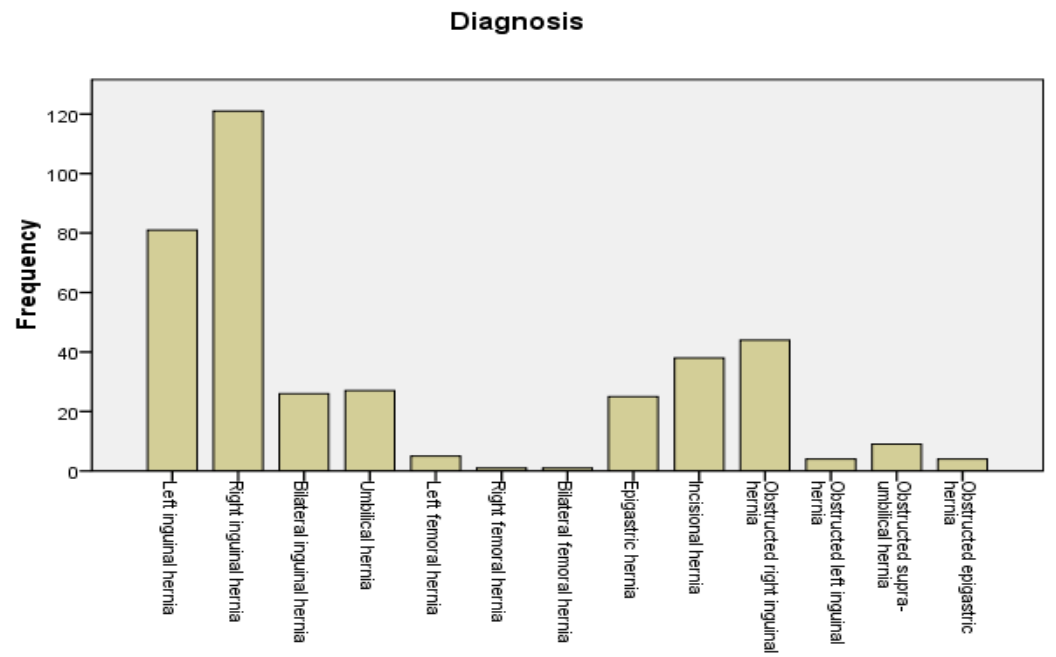

Fig 6 Diagnosis

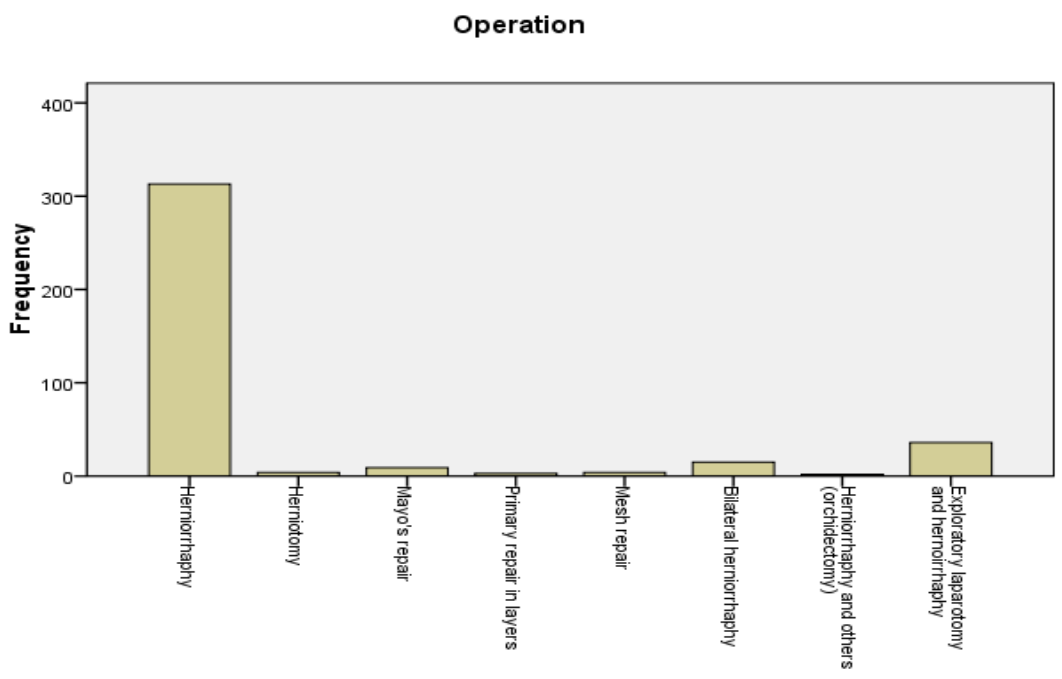

Fig 7 Operation

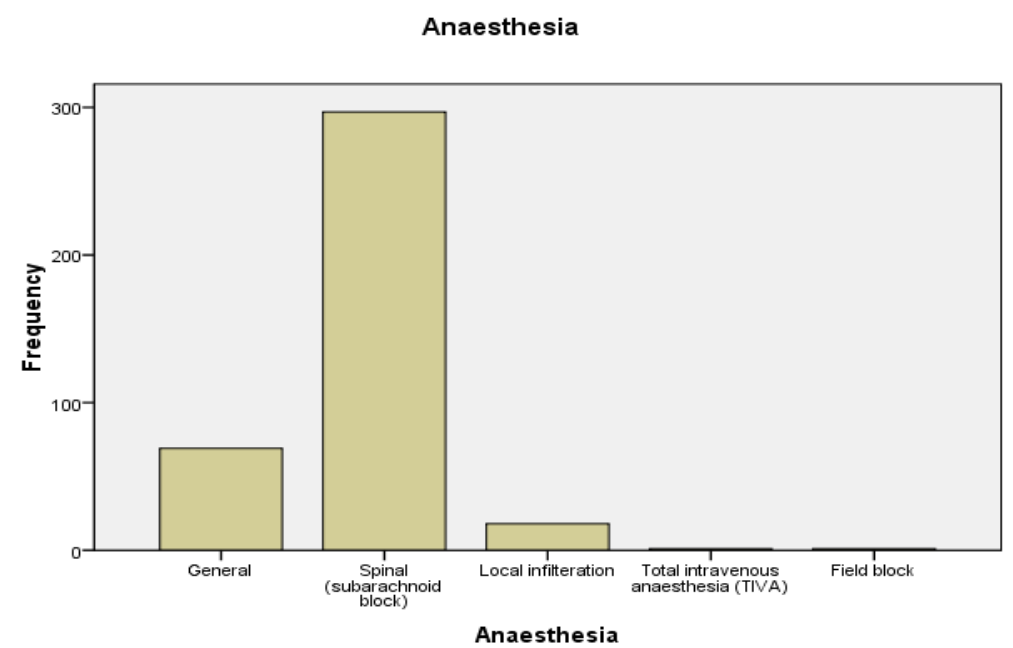

Fig 8 Anaesthesia 


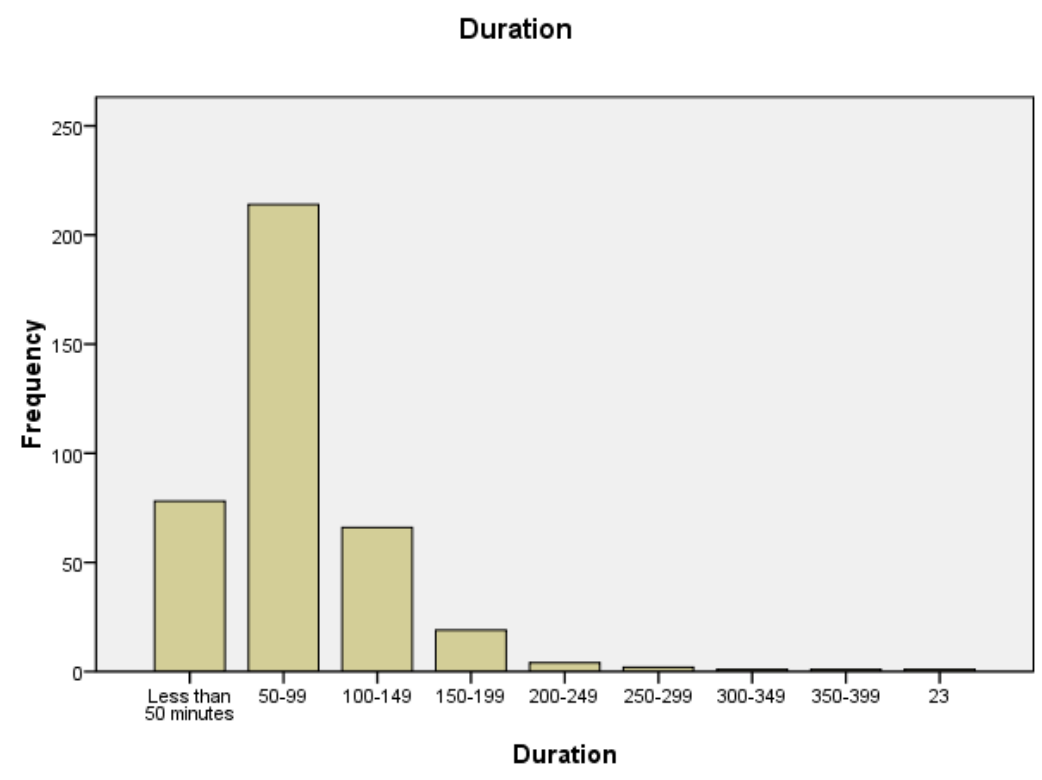

Fig 9 Duration.

\section{Discussion}

History:

The vast majority of hernias are external, easily diagnosed and closely related to the genitalia, they naturally figured prominently in early writings.

As stated by Calson, the earliest mention of an inguinal hernia is found in the Eber's Papyrus (1550 B.C) when the early Egyptian Physicians probably treated inguinal hernia by conservative means. The first description of an operative treatment is attributable to Celsus (25 BC - AD 50) who advised that the operation be done through a groin or scrotal incision. Further impetus for surgical treatment of hernias came in 1867 when Joseph Lister made surgery "safe" by the introduction of aseptic technique. Anatomical studies of Gimbernat (1768), Sir Astley Cooper (1804), Hesselbach (1816), Scarpa (1819) and others whose names are eponyms in the surgical anatomy of the inguinal region laid the basis for great advances in hernia surgery. Invaluable contributions to the evolution of the surgical treatment of hernias have also been made by Alexis Littre (Littre's hernia, 1710: this a hernia sac containing Meckel's diverticulum) DeGarengeot (1768: this is the description of a hernia containing the appendix, also called Amyands.), Richter (Richter's hernia, 1785: this is when the sac contains only a portion of the circumference of bowel wall. In this type of hernia, there may be strangulation without obstruction.) and Scarpa (sliding hernia, 1819: this type of hernia occurs when a viscus forms part of the wall of hernia sac.) ${ }^{2}$. Although Henry O. Marcy of Boston performed herniorrhaphy with narrowing of the internal ring in 1871 , Edoardo Bassini, a Professor of Surgery at the University of Padua, is generally regarded as the first "modern" herniorrhaphist. He presented his operation (first done in 1884) before the Italian Surgical society in 1887. Bassini, in his repair, divided the posterior wall of the inguinal canal from the internal ring down to the pubis and sutured the "cut three fold layers" (transversalis fascia, transverses abdominis and internal oblique) as one layer to the inguinal ligament, behind the cord with interrupted silk sutures. Further contributions were also made by Dr. Halsted (Halsted I Operation, 1889), MacArthur (the use of fascia strips for repair, (1901), Gallie and LeMesurier (free fascial sutures, 1923) and Mair (use of whole thickness skin implant, 1938). Although the first use of Cooper's ligament in inguinal hernia repair is attributed to Lotheissen in 1898, MacVay and Anson popularized it in the 40's. In the early 70's Shouldice in Toronto, refined the Bassini's operation by "double breast" imbrications of transversalis fascia in the Shouldice repair. The construction of a multilayered, overlapping floor repair using continuous sutures of an inert material- darning- has been popularized by Maloney and Glassow among others'. These three repair methods- Bassini, "darning" and shouldice - remain the most extensively used today. Currently, minimal access surgery or closed herniorrhaphy is evolving. This comprises mainly the laparoscopic approach. The laparoscopic techniques in use are the totally extraperitoneal (TEP) and transabdominal preperitoneal (TAPP) approach.

A hernia is the protrusion ${ }^{[1]}$ of an organ or the fascia of an organ through the wall of the cavity that normally contains it. ${ }^{[2]}$ There are different kinds of hernia, each requiring a specific management or treatment. 


\section{Inguinal}

By far the most common hernias (up to $75 \%$ of all abdominal hernias) are the so-called inguinal hernias. Inguinal hernias are further divided into the more common indirect inguinal hernia (2/3, depicted here), in which the inguinal canal is entered via a congenital weakness at its entrance (the internal inguinal ring), and the direct inguinal hernia type (1/3), where the hernia contents push through a weak spot in the back wall of the inguinal canal. Inguinal hernias are the most common type of hernia in both men and women. In some selected cases, they may require surgery.

\section{Femoral}

Femoral hernias occur just below the inguinal ligament, when abdominal contents pass into the weak area at the posterior wall of the femoral canal. They can be hard to distinguish from the inguinal type (especially when ascending cephalad): however, they generally appear more rounded, and, in contrast to inguinal hernias, there is a strong female preponderance in femoral hernias. The incidence of strangulation in femoral hernias is high. Repair techniques are similar for femoral and inguinal hernia.

\section{Umbilical}

They involve protrusion of intraabdominal contents through a weakness at the site of passage of the umbilical cord through the abdominal wall. These hernias often resolve spontaneously. Umbilical hernias in adults are largely acquired, and are more frequent in obese or pregnant women. Abnormal decussation of fibers at the linea alba may contribute.

\section{Incisional}

An incisional hernia occurs when the defect is the result of an incompletely healed surgical wound. When these occur in median laparotomy incisions in the linea alba, they are termed ventral hernias. These can be the most frustrating and difficult to treat, as the repair utilizes already attenuated tissue.

\section{Diaphragmatic}

Diagram of a hiatus hernia (coronal section, viewed from the front).Higher in the abdomen, an (internal) "diaphragmatic hernia" results when part of the stomach or intestine protrudes into the chest cavity through a defect in the diaphragm.

A hiatus hernia is a particular variant of this type, in which the normal passageway through which the esophagus meets the stomach (esophageal hiatus) serves as a functional "defect", allowing part of the stomach to (periodically) "herniate" into the chest. Hiatus hernias may be either "sliding", in which the gastroesophageal junction itself slides through the defect into the chest, or non-sliding (also known as para-esophageal), in which case the junction remains fixed while another portion of the stomach moves up through the defect. Non-sliding or para-esophageal hernias can be dangerous as they may allow the stomach to rotate and obstruct. Repair is usually advised.

A congenital diaphragmatic hernia is a distinct problem, occurring in up to 1 in 2000 births, and requiring pediatric surgery. Intestinal organs may herniate through several parts of the diaphragm, posterolateral (in Bochdalek's triangle, resulting in Bochdalek's hernia), or anteromedial-retrosternal (in the cleft of Larrey/Morgagni's foramen, resulting in Morgagni-Larrey hernia, or Morgagni's hernia).

\section{Other hernias}

Since many organs or parts of organs can herniate through many orifices, it is very difficult to give an exhaustive list of hernias, with all synonyms and eponyms. The above article deals mostly with "visceral hernias", where the herniating tissue arises within the abdominal cavity. Other hernia types and unusual types of visceral hernias are listed below, in alphabetical order:

- Amyand's hernia: containing the appendix vermiformis within the hernia sac

- Busse's Hernia: a testicle within the hernia sac

- Cooper's hernia: a femoral hernia with two sacs, the first being in the femoral canal, and the second passing through a defect in the superficial fascia and appearing almost immediately beneath the skin.

- Epigastric hernia: a hernia through the linea alba above the umbilicus.

- Hiatal hernia: a hernia due to "short oesophagus" — insufficient elongation — stomach is displaced into the thorax

- Littre's hernia: a hernia involving a Meckel's diverticulum. It is named after the French anatomist Alexis Littré (1658-1726).

- Lumbar hernia (Bleichner's Hernia): a hernia in the lumbar region (not to be confused with a lumbar disc hernia), contains the following entities: 
- Petit's hernia: a hernia through Petit's triangle (inferior lumbar triangle). It is named after French surgeon Jean Louis Petit (1674-1750).

- Grynfeltt's hernia: a hernia through Grynfeltt-Lesshaft triangle (superior lumbar triangle). It is named after physician Joseph Grynfeltt (1840-1913).

- Maydl's hernia: two adjacent loops of small intestine are within a hernial sac with a tight neck. The intervening portion of bowel within the abdomen is deprived of its blood supply and eventually becomes necrotic.

- Morgagni hernia: a type of hernia where abdominal contents pass into the thorax through a weakness in the diaphragm

- Obturator hernia: hernia through obturator canal

- Pantaloon hernia (Saddle Bag hernia): a combined direct and indirect hernia, when the hernial sac protrudes on either side of the inferior epigastric vessels

- Paraesophageal hernia

- Paraumbilical hernia: a type of umbilical hernia occurring in adults

- Perineal hernia: a perineal hernia protrudes through the muscles and fascia of the perineal floor. It may be primary but usually is acquired following perineal prostatectomy, abdominoperineal resection of the rectum, or pelvic exenteration.

- Properitoneal hernia: rare hernia located directly above the peritoneum, for example, when part of an inguinal hernia projects from the deep inguinal ring to the preperitoneal space.

- Richter's hernia: a hernia involving only one sidewall of the bowel, which can result in bowel strangulation leading to perforation through ischaemia without causing bowel obstruction or any of its warning signs. It is named after German surgeon August Gottlieb Richter (1742-1812).

- Sliding hernia: occurs when an organ drags along part of the peritoneum, or, in other words, the organ is part of the hernia sac. The colon and the urinary bladder are often involved. The term also frequently refers to sliding hernias of the stomach.

- Sciatic hernia: this hernia in the greater sciatic foramen most commonly presents as an uncomfortable mass in the gluteal area. Bowel obstruction may also occur. This type of hernia is only a rare cause of sciatic neuralgia.

- Spigelian hernia, also known as spontaneous lateral ventral hernia

- Sports hernia: a hernia characterized by chronic groin pain in athletes and a dilated superficial inguinal ring.

- Velpeau hernia: a hernia in the groin in front of the femoral blood vessels

\section{Characteristics}

Hernias can be classified according to their anatomical location:

Examples include:

- abdominal hernias

- diaphragmatic hernias and hiatal hernias (for example, paraesophageal hernia of the stomach)

- $\quad$ pelvic hernias, for example, obturator hernia

- anal hernias

- hernias of the nucleus pulposus of the intervertebral discs

- intracranial hernias

- $\quad$ Spigelian hernia ${ }^{[8]}$

Each of the above hernias may be characterized by several aspects:

- congenital or acquired: congenital hernias occur prenatally or in the first year(s) of life, and are caused by a congenital defect, whereas acquired hernias develop later on in life. However, this may be on the basis of a locus minoris resistantiae (Lat. place of least resistance) that is congenital, but only becomes symptomatic later in life, when degeneration and increased stress (for example, increased abdominal pressure from coughing in COPD) provoke the hernia.

- complete or incomplete: for example, the stomach may partially or completely herniate into the chest.

- internal or external: external ones herniate to the outside world, whereas internal hernias protrude from their normal compartment to another (for example, mesenteric hernias).

- intraparietal hernia: hernia that does not reach all the way to the subcutis, but only to the musculoaponeurotic layer. An example is a Spigelian hernia. Intraparietal hernias may produce less obvious bulging, and may be less easily detected on clinical examination.

- bilateral: in this case, simultaneous repair may be considered, sometimes even with a giant prosthetic reinforcement.

- $\quad$ irreducible: the hernial contents cannot be returned to their normal site with simple manipulation. 
If irreducible, hernias can develop several complications (hence, they can be complicated or uncomplicated):

- strangulation: pressure on the hernial contents may compromise blood supply (especially veins, with their low pressure, are sensitive, and venous congestion often results) and cause ischemia, and later necrosis and gangrene, which may become fatal.

- obstruction: for example, when a part of the bowel herniates, bowel contents can no longer pass the obstruction. This results in cramps, and later on vomiting, ileus, absence of flatus and absence of defecation.

- dysfunction: another complication arises when the herniated organ itself, or surrounding organs, start to malfunction (for example, sliding hernia of the stomach causing heartburn, lumbar disc hernia causing sciatic nerve pain, etc.).

\section{Treatment}

For a hernia like inguinal hernia, surgery is no longer recommended in most cases. However, it is in few cases advisable to repair some other kinds of hernias, in order to prevent complications such as organ dysfunction, gangrene and multiple organ dysfunction syndrome. Most abdominal hernias can be surgically repaired, but surgery often has complications, such as chronic groin pain. Time needed for recovery after treatment is greatly reduced if hernias are operated on laparoscopically, the minimally invasive operation most commonly used today. ${ }^{[9]}$ Uncomplicated hernias are principally repaired by pushing back, or "reducing", the herniated tissue, and then mending the weakness in muscle tissue (an operation called herniorrhaphy). If complications have occurred, the surgeon will check the viability of the herniated organ, and resect it if necessary.

Muscle reinforcement techniques often involve synthetic materials (a mesh prosthesis). The mesh is placed either over the defect (anterior repair) or under the defect (posterior repair). At times staples are used to keep the mesh in place. These mesh repair methods are often called "tension free" repairs because, unlike some suture methods (e.g. Shouldice), muscle is not pulled together under tension. However, this widely used terminology is misleading, as there also exists many tension-free suture methods that do not use mesh (e.g. Desarda, Guarnieri, Lipton-Estrin...).

Evidence suggests that tension-free methods (with or without mesh) often have lower percentage of recurrences and the fastest recovery period compared to tension suture methods. However, among other possible complications, prosthetic mesh usage seems to have a higher incidence of chronic pain and, sometimes, infection. ${ }^{[10]}$

One study attempted to identify the factors related to mesh infections and found that compromised immune systems (such as diabetes) was a factor. ${ }^{[\text {dead link } k[11]}$ Mesh has also become the subject of recalls and class action lawsuits. ${ }^{\text {[dead link }][12]}$

Laparoscopic surgery is also referred to as "minimally invasive" surgery, which requires one or more small incisions for the camera and instruments to be inserted, as opposed to traditional "open" or "microscopic" surgery, which requires an incision large enough for the surgeon's hands to be inserted into the patient. The term microscopic surgery refers to the magnifying devices used during open surgery.

Many patients are managed through day surgery centers, and are able to return to work within a week or two, while intensive activities are prohibited for a longer period. Patients who have their hernias repaired with mesh often recover in a number of days, though pain can last longer, and often forever. Surgical complications have been estimated to be more than 20 percent. They include chronic pain, surgical site infections, nerve and blood vessel injuries, injury to nearby organs, and hernia recurrence.

Due to surgical risks, mainly chronic pain risk, the use of external devices to maintain reduction of the hernia without repairing the underlying defect (such as hernia trusses, trunks, belts, etc.) are often used. In particular, we can mention uncomplicated incisional hernias that arise shortly after the operation (should only be operated after a few months), or inoperable patients. There have been known cases where hiatal and esophageal hernias have shown signs of improvements after the patient stopped producing stress on the affected area by fasting or parenteral nutrition. It is essential that the hernia not be further irritated by carrying out strenuous labour.

The prevalence of inguinal hernia in general population is difficult to ascertain. In some instances, it may not be completely obvious or even demonstrable. Worldwide, it is estimated that inguinal hernia affects 6$12 \%$ of the population. In the United States of America, it is estimated that inguinal hernia occurs in about 500,000 cases each year.Zendejas et al reported incidence of hernia repair in Olmsted County, Minnesota: a population -based study done in Mayo clinic, Rochester, USA from 1989 to 2008. They concluded that inguinal hernias are common. Also, hernia incidence varies greatly by age and sex and has decreased substantially over time in Olmsted County, Minnesota, USA

Elliis reported in Britain that about 5\% of the population has an inguinal hernia and repairing these accounted for about $10 \%$ of general surgical operations. Sixty percent were right, $20 \%$ were left and $20 \%$ were 
bilateral. In Africa, a rural survey for inguinal hernia in Ghananian adult males above 15 years, showed overall prevalence of $7.7 \%^{14}$. A prevalence of $9 \%$ was reported among Zimbabwean miners and 16\% in Tanzanian hospital out-patient population'.

Inguinal hernia remains the most common type of external hernia both among Africans and Caucasians. Zimmerman and Anson estimated that of every thousand hernias in the general American population, $825(82.5 \%)$ were inguinal hernia, 65 incisional, 45 femoral, 35 umbilical and 30 miscellaneous ${ }^{29}$. Nyhus et al also had a similar distribution though the percentage of inguinal hernia (75\%) was lower ${ }^{12}$. Constance et al examined risk factors for incident inguinal hernia among US adult population participated in the First National Health and Nutrition Examination survey 1971 to 1975. A total of 5,316 men and 8,136 women were followed up through 1992-1993 for a hospital (International Classification of Diseases, Ninth Revision, Clinical Modification, code 550) or physician diagnosis of inguinal hernia. Ninety-six percent of the baseline cohort was recontacted, with a median follow-up of 18.2 years (range of 0.02-22.1 years) .Because the cumulative incidence of inguinal hernia was higher among men (13.9\%) than among women $(2.1 \%)$, more detailed analyses were conducted in men. Among men in the multivariate analyses, a higher incidence $(\mathrm{P}<0.05)$ of inguinal hernia was associated with age of 40-59 years. In Zaria, of 2,011 cases operated upon in a 2-year period reported by Onukak et al , 92.4\% had inguinal 2.8 epigastric, 1.7 femoral,1.6 Umbilical, $0.9 \%$ incisional and $0.5 \%$ miscellaneous. This was similar to that reported by Badoe in Ghana, in which out of 1188 external hernias reviewed, $92 \%$ were inguinal, $2 \%$ femoral, $4 \%$ umbilical and $1 \%$ incisional.

The sex prevalence has not been clearly elucidated. Statistics from America and Britain showed female to male ratio of $2: 1^{4,5}$. Some African studies have contrary report of female to male ratio of $1: 2^{\prime}$, On the average, external hernias especially inguinal are more common among males than females with a female to male ratio estimated to be between $1: 10$ and $1: 12^{3,22,26}$. The difference is probably attributable to the size of the spermatic cord in male producing far more potential weakness of the inguinal canal than the narrower round ligament of female. It is attributable also to the more active life of female.

Badoe reported in 1973 that the age incidence in third, fourth and fifth decade of life were $29.55 \%$, $20.5 \%$ and $13.3 \%$ respectively ${ }^{30}$. Belcher in 1978 showed that the prevalence increases with age above 55 years among Ghananian rural dwellers ${ }^{14}$. Onukak et al in Zaria, Nigeria, noted that the majority of patients were famers aged between 30 and 50 years ${ }^{22}$. Archampong et al reported age incidence to be peaked in the $3^{\text {rd }}$ and $4^{\text {th }}$ decades

The precipitating factors have not been consistent in many studies. One of the factors is sustained increase in intra-abdominal pressure which may result from any cause such as regular manual labour, cough, constipation and bladder outlet obstruction. None of these have been consistent in patients with hernia. Hernia can be seen in individual who had not changed his habit before herniation. Many patients may never develop a hernia despite a life of vigorous physical activities. Evans in 1961 showed that inguinal hernias present in adult males seeking employment as heavy manual labourers and the appearance of the hernias could not be correlated with actual engagement in heavy manual labourer ${ }^{28}$. Belcher in Ghana found no significant difference between farmers and non-farmers in prevalence of hernia; $7.8 \%$ in farmers and $7.2 \%$ in non-farmers. In a case control study on the risk factors of inguinal hernia in adults, Lau et al reported a higher work activity index, a higher total activity index, a positive family history of inguinal hernia and chronic obstructive airway disease. They concluded that family history of hernia was the most important determinant factor for developing inguinal hernia in adults in males. A male subject who has a positive family history of hernia is 8 times more likely to develop a primary inguinal hernia .

Ashindoitiang et al conducted a case control studyat General surgical clinic, of Ikorodu General Hospital between April 2009 and March 2011, on the risk factors for inguinal hernia in adult male Nigerian patients aged 18 years and above who presented with primary inguinal hernia. They found among 404 patients who were interviewed ( 202 were the controls while 202 who were the cases) that the significant risk factors for inguinal hernia were positive family history of inguinal hernia $\mathrm{p}<0.001$ and strenuous work activities $\mathrm{p}<$ 0.001. Among these cases, $132(65.3 \%)$ had indirect hernia while the remaining $70(34.7 \%)$ had direct hernia. Positive family history $\mathrm{p}<0.05$ and straining during urination or defaecation $\mathrm{p}<0.05$ were the factors significantly associated with the type of hernia. They concluded that family history of inguinal hernia and strenuous work activity are significant risk factors for this condition in their setting

In Africa, hernia remains a major surgical burden. It imposes a lot in demand in medicare. OheneYeboah et al studied inguinal hernia disease in Africa using Conchrane central Register of controlled trials and EMBASE. They selected all journals on inguinal hernia performed in Africa and published in World journals from 1990-2010. Their result revealed dearth of knowledge of the burden of inguinal hernia in the various communities in Africa, especially in sub-Saharan Africa. There were no population-based studies in the subSaharan context that could profer information on the epidemiology of inguinal hernias from which to estimate the necessity for surgery in Africa. They concluded that there is a large disease burden in Africa and a limited surgical capacity to reduce the burden. They also advocated the formation of an African hernia society to partner 
with corporate and international organizations to make hernia a public health concern. They recommended use of population-based studies, to determine the actual burden of disease in Africa and to take modern hernia surgery to most parts of the continent

Complications of Groin Hernia Repairs may be early or late.

Early will include: Injury to adjacent structures such as the vas deferens, the nerve Iliohypogastric, IlioinguinalGenitofemoral, Lateral cutaneous, Cord and testicular, Hematoma, Ischemic orchitis, Testicular atrophy, Hydrocele, Testicular descent, Bladder injury,Wound infection, hematoma, seroma, acute urinary retention,osteitis pubis, Anaestitic complications. In case of laparoscopy, general anaethesia complications, air embolism, pot site infection, prosthetic complications, bowel perforation, diaphragmatic dysfunction, and hypercapnia.

Late complications will include: recurrence, adhesions, intestinal obstruction and keloids.

Complications may arise post-operation, including rejection of the mesh that is used to repair the hernia. In the event of a mesh rejection, the mesh will very likely need to be removed. Mesh rejection can be detected by obvious, sometimes localised swelling and pain around the mesh area. Continuous discharge from the scar is likely for a while after the mesh has been removed.

A surgically treated hernia can lead to complications, while an untreated hernia may be complicated by:

- Inflammation

- Irreducibility

- Obstruction of any lumen, such as bowel obstruction in intestinal hernias

- Strangulation

- Hydrocele of the hernial sac

- Haemorrhage

- Autoimmune problems

- Incarceration, which is where it cannot be reduced, or pushed back into place, ${ }^{[13]}$ at least not without very much external effort. ${ }^{[14]}$ In intestinal hernias, this also substantially increases the risk of bowel obstruction and strangulation.

\section{Signs and symptoms}

By far the most common hernias develop in the abdomen, when a weakness in the abdominal wall evolves into a localized hole, or "defect", through which adipose tissue, or abdominal organs covered with peritoneum, may protrude. Another common hernia involves the spinal discs and causes sciatica. A hiatal hernia occurs when the stomach protrudes into the mediastinum through the esophageal opening in the diaphragm.

Hernias may or may not present with either pain at the site, a visible or palpable lump, or in some cases more vague symptoms resulting from pressure on an organ which has become "stuck" in the hernia, sometimes leading to organ dysfunction. Fatty tissue usually enters a hernia first, but it may be followed or accompanied by an organ.

Symptoms may or may not be present in some inguinal hernias, while in some other hernias they are. Symptoms and signs vary depending on the type of hernia. In the case of reducible hernias, a bulge in the groin or in another abdominal area can often be seen and felt. When standing, such a bulge becomes more obvious. Besides the bulge, other symptoms include pain in the groin that may also include a heavy or dragging sensation, and in men, there is sometimes pain and swelling in the scrotum around the testicular area. ${ }^{[3]}$

Irreducible abdominal hernias or incarcerated hernias may be painful, but their most relevant symptom is that they cannot return to the abdominal cavity when pushed in. They may be chronic, although painless, and can lead to strangulation. Strangulated hernias are always painful and pain is followed by tenderness. Nausea, vomiting, or fever may occur in these cases due to bowel obstruction. Also, the hernia bulge in this case may turn red, purple or dark and pink.

In the diagnosis of abdominal hernias, imaging is the principal means of detecting internal diaphragmatic and other nonpalpable or unsuspected hernias. Multidetector CT (MDCT) can show with precision the anatomic site of the hernia sac, the contents of the sac, and any complications. MDCT also offers clear detail of the abdominal wall allowing wall hernias to be identified accurately. ${ }^{[4]}$

\section{Conclusion}

Hernia in South Southern Nigeria has quite a large magnitude of clinical impact in our environment. The indirect inguinal hernia being the most common with male sex preponderace. Sub-aracnoid block if the most form of anaesthesia utilized with most herniorrhaphies done by the senior registrars.

\section{Acknowledgement}

We thank all consultants in General Surgery for using their patients and also Statistitian Nduka Nwonu for providing immense assistance in data analysis. 


\section{References}

[1]. Alade RB, Itayemi SO, Alufohai E. Hernia in: Adeloye, A. ed. Davey's Companion to surgery in Africa. $2^{\text {nd }}$ ed. Church Hill Livingstone, Edinburgh, London Melbourne and New York 1987.

[2]. Malangoni MA, Rosen MJ. Hernias. In: Townsend CM, Beauchamp RD, Evers BM, Mattox KL. Sabiston textbook of surgery: the biological basis of modern surgical practice $19^{\text {th }}$ edition. Saunders, an imprint of Elsevier Inc 2012: 1114-1128.

[3]. Nyhus LM, Thomas Bonbeck C Hernias In : Sabiston, D.Ced Text book of Surgery 19 ${ }^{\text {th }}$ ed. W. B. Saunders Company Philadelphia, London, Toronto 1981.

[4]. Zollinger RM Jr. Classification systems for groin hernias. Surgical Clinics of North America, 2003; 83: $1053-1063$.

[5]. ScorerCG, Graham HF, Congenital anomalies of the testis in: Campbell Urology. 6th Ed. Vol 2 W. B. Saunder's company1979

[6]. Nwako FA Hernia and Hydrocele. In: Nwako FA ed, A Textbook of Paediatic Surgery in the Tropics. The Macmillian Press Ltd. London and Basingstoke 1980.

[7]. Bakwin H. Indirect inguinal hernia in twins. J. Pediat Surg 1971; 6: 165-168

[8]. Belcher DW, Nyame PK, W. Wurapa FK. The prevalence of inguinal hernia in adult. Ghananian males. Trop Geogr Med 1978; 30: $39-43$

[9]. Nylander PPS Biochemical aspects of multiple births. J Biosoc Sci 1971; 3: 29

[10]. Zivanovic S. The anatomical basis for the high frequency of inguinal and femoral hernia in Uganda. E Afr Med J 1968; 45 : $41-46$.

[11]. Gogler H. Hernia in rural Togo (West Africa). W. Afr. Med. J 1973; 22: 64-66

[12]. Read RC, White HJ. Inguinal herniation. Am. J. Surg. 1978; 136:651-654.

[13]. Peacock EE Jr, Madden JW. Studies of the biology and treatment of recurrent inguinal hernia II. Morphological changes. Ann Surg 1974; 179: 567-571

[14]. Dodiyi-Manuel A. Adult intestinal obstruction in Braithwaite Memorial Specialist Hospital, Port Harcourt, Nigeria: a 3-year review. Port Harcourt Medical Journal (PMJ) 2012;6: 308-312.

[15]. Etawo US, Maduforo CO. A five year audit of acute mechanical intestinal obstruction in adults in Port Harcourt, Nigeria. Port Harcourt Medical Journal (PMJ) 2012;6: 292-298.

[16]. Carlson RI, The historical development of the surgical treatment of inguinal hernia. Surg 1956; 39: 1031-1045.

[17]. Ellis H. Inguinal hernia. Brit J Hosp Med1970; 4: 9-14.

[18]. Morton JH Abdominal wall Hernias in: Schwatz SI, Shines TG, Spencer FC, Storer EH eds. Principles of surgery $5^{\text {th }}$ Edition. McGraw-Hill Book Company. New York 1984.

[19]. Lytle WJ. The deep ring, development, function and repair. Brit J Surg.1970; 57: 531-536.

[20]. Zimmerman LM. A critique of the McVay operation for inguinal hernia. Surg. Obst. And Gynae 1948; 87: $621-623$.

[21]. Devlin HB, Gillen PHA, Waxman BP, MacNay RA. Short stay surgery for inguinal hernia: experience of the Shouldice operation 1970-1982. Brit J Surg 1986 73: 123-124.

[22]. Maloney GE, Gill WG, Baclay RC. Operations for hernia. Technique of nylon darn. The Lancet 1948; 2: 45-48.

[23]. Glassow F. Inguinal hernia repair, a comparison of Shouldice and Cooper ligament repair of the posterior Inguinal wall. Am J Surg 1976; 131: 306

[24]. Andrew N K. Hernia surgery: from guidelines to Clinical Practice. Ann R Coll Surg Eng 2009; 9: $273-279$.

[25]. Zendejas B, Ramirez T, Jones T, Kuchena A, Ali SM, Hernandez-Irizarry R, Lohse CM, Failey DR . Incidence of inguinal hernia repairs in Olmsted County, MN: a population-based study. Ann Surg 2013; 257: 520-526

[26]. Glassow F Inguinal hernia repair using local anaesthesia. Ann R Coll Surg Engl, 1984; 66: 382-387.

[27]. Holzheimer RG. Inguinal hernia classification, diagnosis and treatment- classic, traumatic and Sportsman's hernia. Eur J Med Res. 2005; 10: 121-134

[28]. Ruhl CE, Everhart JE. Risk factors for inguinal hernia among adults in the US population. Am J Epidemiol. $2007 ; 165: 1154-1161$.

[29]. Onukak EE, Grundy DJ, Lawrie JH. Hernia in Northern Nigeria. Journal of Royal College of Edinburgh 1983; 28:147-150.

[30]. Badoe EA, Archampong EQ, da Rocha-Afodu JT, Hernia( Excluding Diaphragmatic Hernia). In: Badoe EA, Archampong EQ, da Rocha-Afodu JT eds. Principles and practice of surgery, including pathology in tropics fourth edition. Ghana publishing corperation, PMB Tema 2009: 524-545.

[31]. Kingsnorth A, LeBlanc K Hernias: inguinal and incisional, Lancet 2003; 362: 1561-1571.

[32]. Adesunkanmi AR. Badmos TA, Salako AA Groin hernias in patients 50 years of age and above. Pattern and outcome of management in 250 consecutive patients. West Afr J Med. 2000; 19: 142-147

[33]. Adesukami AR, Agbakwuru EA, Badmus TA. Obstructed abdominal hernia at the Wesley Guild Hospital, Nigeria. East Afr Med J 2000; 77: 31-33.

[34]. Archampong EO, Owusu PA, Amankwa JA. The pattern of acute intestinal obstruction at Korle Bu Teaching Hospital. W African J of Med 1984; 3: 263-270.

[35]. Lau H, Fang C, Yuen WK, Patil NG. Risk factors for inguinal hernia in adult males: a case-control study. Surgery. 2007;141:262266.

[36]. Ashindoitiang JA, Ibrahim NA, Akinlolu OO. Risk factors for inguinal hernia in adult male Nigerians: a case control study. Int J Surg 2012; 10:364-367

[37]. Ohene-Yeboah M, Abantanga FA. Inguinal hernia disease in Africa: a common but neglected surgical condition. West Afr J Med. $2011 ; 30: 77-83$. 